\title{
Correlation Study of Physicochemical, Rheological, and Tribological Parameters of Engine Oils
}

\author{
Prashant Thapliyal $^{1,2}$ and G. D. Thakre ${ }^{3}$ \\ ${ }^{1}$ Department of Physics, Army Cadet College, Indian Military Academy, Dehradun 248007, India \\ ${ }^{2}$ Uttarakhand Technical University, Sudhowala, Dehradun 248007, India \\ ${ }^{3}$ Tribology and Combustion Division, CSIR-Indian Institute of Petroleum, Mohkampur, Dehradun, India \\ Correspondence should be addressed to Prashant Thapliyal; prashant.197104@gmail.com
}

Received 4 March 2017; Accepted 9 May 2017; Published 8 June 2017

Academic Editor: Meng Hua

Copyright (C) 2017 Prashant Thapliyal and G. D. Thakre. This is an open access article distributed under the Creative Commons Attribution License, which permits unrestricted use, distribution, and reproduction in any medium, provided the original work is properly cited.

\begin{abstract}
The physicochemical and tribological studies of mineral and synthetic commercial engine oils have been carried out to investigate their performance variability and to propose generalized relationship among different physicochemical and performance parameters. Physicochemical parameters have been determined using standard test procedures proposed in ASTM and Indian Standards (BIS). The rheological parameters of these lubricants have been investigated to identify the flow behavior. The tribological performance in terms of their antifriction and antiwear properties has been studied using four-ball tribotester. Correlation and regression analysis has been performed to ascertain relationship among physicochemical and tribological parameters and the causes of performance variability are highlighted. An empirical relation to calculate coefficient of friction as a function of physicochemical properties has been established using regression analysis. The developed relation has fair degree of reliability, as percentage of deviation is less than $20 \%$.
\end{abstract}

\section{Introduction}

Lubricants play a vital role in present day automotives. The engine oils in particular lubricate all the critical parts of IC engines. They not only reduce friction and wear between the moving parts but also dissipate frictional heat generated between the contacting parts of the engines [1]. The engine oils are basically formulated using base oil and additive package. The chemistry of formulated engine oil by and large determines its physicochemical properties and also the in situ tribo performance behavior. The physicochemical properties like viscosity, density, TAN (total acid number), TBN (total base number), and sulphated ash are considered to be important characteristic properties of the engine oils. These properties provide information on general applicability of engine oils. Along with physicochemical properties, the flow behavior of engine oils is also an important aspect. The flow behavior of engine oil is dependent on the rheology of the oil and, therefore, it is very much essential to have a thorough knowledge of the rheological behavior of the lubricants [2].

The lubricants on the basis of their rheological behavior are characterized as Newtonian and non-Newtonian fluids. The fluids with molecular mass less than $1000 \mathrm{~kg} / \mathrm{mol}$ show Newtonian behavior at low pressure and shear stress [3]. Recently it has been reported that the non-Newtonian behavior of lubricants results into improved load carrying capacity and reduced contact friction in hydrodynamic porous journal bearings [4]. The engine oils exhibit viscoelasticity under non-Newtonian flow condition and show time dependent strain [5]. Viscoelasticity results in shear thinning of lubricants. Therefore, the viscosity of engine oil is considered to be one of the major rheological parameters that have profound influence on the lubricant performance behavior. Thus, the physicochemical properties and rheological and tribological behavior of engine oils are interdependent.

Tribology is the study of friction and wear of the machine parts. Lubricating oil forms a thin film between the surfaces 
TABLE 1: Lubricants selected for the study.

\begin{tabular}{lcccc}
\hline Sl. number & Lubricant code & SAE grade & Base oil & Application \\
\hline 1 & $\mathrm{~L}_{1}$ & SAE-40 & Mineral & Diesel engine \\
2 & $\mathrm{~L}_{2}$ & SAE20W-50 & Mineral & Diesel/gasoline engine \\
3 & $\mathrm{~L}_{3}$ & SAE20W-50 & Mineral & Gasoline engine \\
4 & $\mathrm{~L}_{4}$ & SAE5W-40 & Synthetic & Diesel/gasoline engine \\
5 & $\mathrm{~L}_{5}$ & SAE5W-40 & Synthetic & Diesel/gasoline engine \\
\hline
\end{tabular}

that separates adjacent moving parts and minimizes the direct contact between them. As a result of this, the heat generated due to frictional heating decreases. Efficient lubrication aids in wear reduction, thus protecting the engine components from frequent failures. On the basis of the ratio of lubricant film thickness to the composite surface roughness of the contacting surfaces, different lubrication regimes ranging from boundary to hydrodynamic lubrication may occur. These lubrication regimes have dependency on the contact pressure and on the surface velocity of the surfaces in contact [6]. In this context, experimental-statistical methods have been extensively used to characterize friction in dry contact and second-order polynomial equation established for coefficient of friction [7]. In another attempt differentiation between API GL performance levels of automotive gear oils was conducted using tribological tests on four-ball and crossed-cylinder wear test apparatus. The statistical analysis performed has revealed the differentiation in performance levels of automotive gear oils [8].

Interrelationship among various physicochemical and tribological parameters can be an effective tool to understand the behavior and performance variability of lubricants. Various attempts have been made to establish empirical relations among physicochemical parameters using mathematical/statistical techniques. In this context, variation in tribo performance of commercial engine oils was studied and correlations between tribological parameters like friction and wear with physicochemical properties were established [9]. Similarly empirical relations were established between temperature and absolute viscosity for lubricants derived from seed oils [10]. In order to predict the tribological properties an algorithm called phenomenological and predictive model was developed for organic sulphide based lubricants. The model was validated using experimental data on weld load using four-ball machine [11]. Over the years, it has been observed that the theoretical models have been used to rationalize experimental data on the physicochemical properties of binary mixtures of vegetable oils with various classes of mineral base oils [12]. Moreover, multivariable statistical analyses techniques have been used for predicting the pressure viscosity coefficient of lubricants using NMR experiments [13].

A number of studies have been carried out in the past on determining and establishing the dependency among different lubricant parameters since Barus established a relation between viscosity and pressure by introducing pressure viscosity coefficient " $\alpha$ " [14]. In the recent past comprehensive characterization of lubricating fluids of same viscosity but different additive and base stock compositions was performed to investigate the frictional behavior, thermophysical and rheological properties, and mechanical efficiency in hydraulic motors [15]. The lubricant viscosity is temperature dependent. Studies have been carried out to establish the dependency of temperature and other parameters on viscosity of engine oil. Relationship between shear dependent viscosity, temperature, and pressure for polymer thickened lubricants was also established [16]. It has been reported that better rheological behavior with temperature leads to better tribological performance [17].

On the basis of literature review carried out it is observed that attempts have been made to develop dependencies among various characteristic properties of the lubricants. However, no comprehensive dependency in the form of empirical relations between the physicochemical properties and tribological performance of the engine oil exists. Hence, in the present work attempts have been made to investigate the relations between the physicochemical properties and the tribological performance of engine oils. The study has been performed on commercial engine oils and the characteristic properties pertaining to physicochemical, rheological, and tribological performance determined. The performance parameters were then correlated using correlation and regression analysis to establish dependency relations among them. The study will aid the lubrication and maintenance engineers in selecting appropriate parameters for the successful operations of the engines.

\section{Experimental}

2.1. Lubricant Selection. In this study, five different commercial engine oils coded as $\mathrm{L}_{1}, \mathrm{~L}_{2}, \ldots, \mathrm{L}_{5}$ have been considered. The details of the selected lubricants are given in Table 1. The motive behind selecting the said lubricants is to understand the performance behavior of lubricants presently available in the market and establish relations among their characteristic properties and performance behavior.

2.2. Lubricant Characterization. The selected lubricants have been characterized for their physicochemical properties, rheological behavior, and tribological performance. The physicochemical properties provide the basic qualitative information on the products selected while the rheological and tribological behaviors provide the information on performance of the lubricants. The TAN measures the presence of organic and strong inorganic acids in the oil and is an indicator of oil oxidation that may lead to corrosion of the components. TBN 
being the measure of basic components represents the ability of oil to neutralize acids produced in it during normal use. Similarly, sulphated ash represents the amount of metallic elements derived from the detergent and antiwear additives of the oil. The additive packages contain elements like calcium, magnesium, zinc, molybdenum, phosphorus, and so on that help in enhancing the performance of the engine oil.

2.2.1. Physicochemical Properties. The physicochemical properties such as density, viscosity, viscosity index, sulphated ash, total acid number (TAN), and total base number (TBN) have been determined using standard test procedures proposed in ASTM and Indian Standards (BIS). The metallic elements present in the additive package have been determined using the Inductively Coupled Plasma Atomic Emission Spectrometer (ICPAES), model: PS 3000 UV (DRE), Leeman Labs Inc. (USA).

2.2.2. Rheology. The variation of rheological parameters (viscosity, shear stress, and torque) with temperature has been investigated using RHEOPLUS/32 MCR 302 from Anton Paar Austria. The rheometer capable of performing rheological studies in rotational or oscillatory mode consists of an EC motor with a torque range of $10-200 \mathrm{mNm}$. The experiments have been performed using concentric cylinder geometry as shown in Figure 1. The clearance space between the concentric cylinders was filled with the lubricant to be tested and the inner cylinder was rotated with the help of a spindle at the desired speed. Two different sets of experiments were performed to determine the variation of coefficient of viscosity with temperature and the shear rate. The first set of rheology experiments was performed at a constant shear rate of $10 / \mathrm{s}$ and the temperature was varied from 20 to $50^{\circ} \mathrm{C}$ with variation rate of $4^{\circ} \mathrm{C}$ per minute. The variation in coefficient of viscosity with temperature was monitored and recorded. In yet another experiment, the shear rate was varied from 1 to $100 / \mathrm{s}$ at room temperature and the variation in coefficient of viscosity with shear rate was monitored and recorded.

2.2.3. Tribology. Tribological performance tests have been conducted on four-ball tribotester (FBT) using the standard wear test procedure as mentioned in ASTM D: 4172B. The FBT used in the present study is shown in Figure 2.

(1) Friction Analysis. The FBT machine assesses antiwear and antifriction properties of lubricants. For this the FBT utilizes a four-ball sliding contact geometry formed in between four balls each of diameter $12.7 \mathrm{~mm}$. The four balls are assembled in a tetrahedron with bottom three balls fixed in the ball pot while the fourth ball mounted on the vertical shaft is free to rotate at predefined spindle speed. The lubricant to be tested is introduced in the stationary ball pot forming thin lubricating film between the bottom three and the top ball. The contact friction in terms of friction torque is continuously recorded during the entire test duration.

(2) Wear Analysis. The contact wear in terms of wear scar diameter is measured at the end of the test using an industrial apochromatic microscope. The friction torque is later converted into coefficient of friction using empirical relations.
TABLE 2: Experimental test condition.

\begin{tabular}{lc}
\hline Parameter & Value \\
\hline Load & $40 \mathrm{kgf}$ \\
Temperature & $75^{\circ} \mathrm{C}$ \\
Speed & $1200 \mathrm{rpm}$ \\
Test duration & $1 \mathrm{hr}$ \\
\hline
\end{tabular}

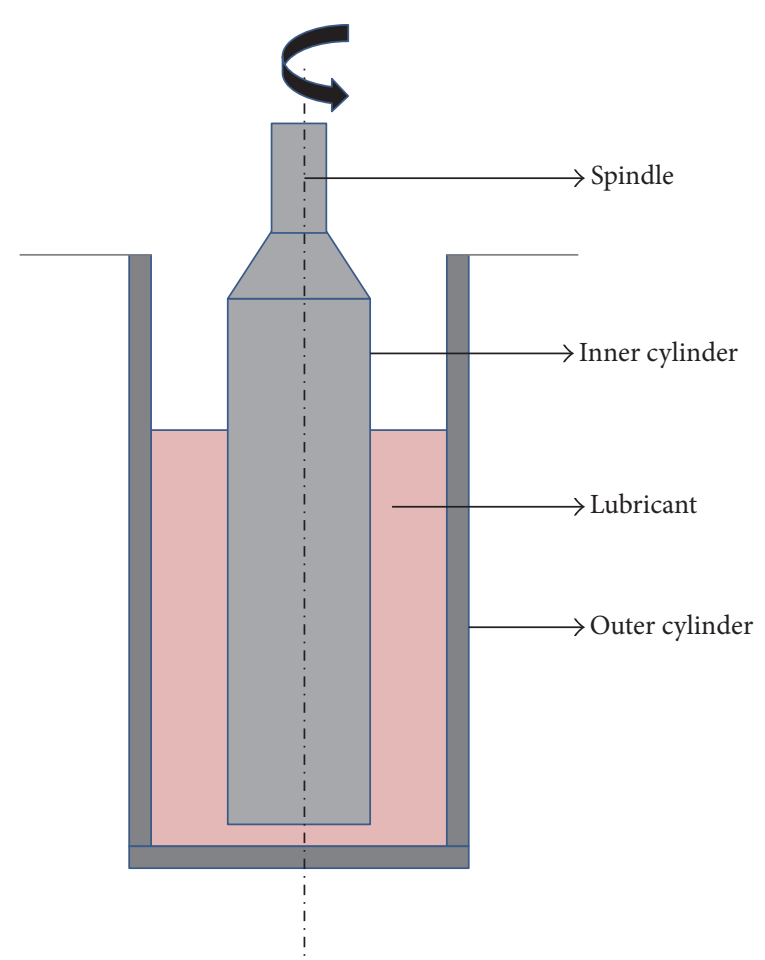

Figure 1: Concentric cylindrical geometry of rheometer.

Each lubricant is tested twice and the wear scar diameter (WSD) along the vertical and horizontal axis is measured for all the bottom three balls, thus providing 12 readings for a given lubricant. The average of the 12 readings is reported as the wear scar diameter.

The experiments are performed on balls made up of AISI chrome alloy standard steel number E- 52100, grade $25 \mathrm{EP}$ (extra polish). The test conditions used are given in Table 2.

Postexperimental investigations on the used test specimens were performed to investigate the mode and mechanism of wear. Further, the capability of additives to form boundary layers on the test surface was investigated using scanning electron microscopy (SEM) using FESEM from FEI Netherlands model Quanta 200F fitted with EDX system.

\section{Results and Discussion}

3.1. Physicochemical Analysis of Lubricants. The results for the measurements carried out on the physicochemical properties of the lubricants are given in Table 3 .

It is evident from Table 3 that commercial engine oils are nearly similar in their physicochemical characteristics. The density of these lubricants is of the order of $0.8 \mathrm{~g} \mathrm{~cm}^{-3}$, 
TABLE 3: Physicochemical properties of the lubricants.

\begin{tabular}{|c|c|c|c|c|c|c|}
\hline \multirow{2}{*}{ Sl. number } & \multirow{2}{*}{ Characteristics } & \multicolumn{5}{|c|}{ Lubricant name } \\
\hline & & $\mathrm{L}_{1}$ & $\mathrm{~L}_{2}$ & $\mathrm{~L}_{3}$ & $\mathrm{~L}_{4}$ & $\mathrm{~L}_{5}$ \\
\hline 1 & Density at $15^{\circ} \mathrm{C}\left(\mathrm{g} \mathrm{cm}^{-3}\right)$ & 0.8711 & 0.8910 & 0.8695 & 0.8655 & 0.8526 \\
\hline 2 & Kinematic viscosity $\left(\mathrm{mm}^{2} / \mathrm{s}\right) @ 40^{\circ} \mathrm{C}$ & 123.06 & 166.71 & 154.93 & 83.68 & 79.82 \\
\hline 3 & Kinematic viscosity $\left(\mathrm{mm}^{2} / \mathrm{s}\right) @ 100^{\circ} \mathrm{C}$ & 14.17 & 17.75 & 17.93 & 13.28 & 13.05 \\
\hline 4 & Viscosity index (VI) & 115 & 117 & 118 & 162 & 166 \\
\hline 5 & TAN (mg KOH/g) & 0.44 & 1.93 & 0.93 & 2.13 & 2.00 \\
\hline 6 & TBN (mg KOH/g) & 11.16 & 11.09 & 9.65 & 14.41 & 14.25 \\
\hline 7 & Sulphated ash \%wt & 1.06 & 0.77 & 0.93 & 0.80 & 1.10 \\
\hline
\end{tabular}

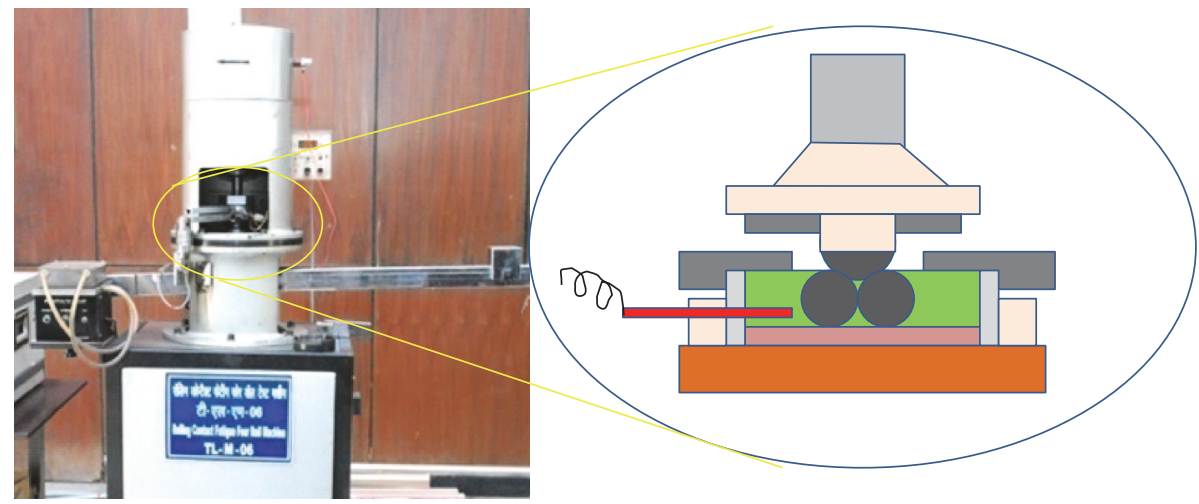

FIgURE 2: Four-ball tribotester (FBT).

irrespective of the brand of lubricant and the nature of base oil (mineral/synthetic). The tested lubricants have VI > 110 . However, the synthetic lubricants have very high VI of above 160. A high VI is very much desired so that there is lesser variation in viscosity with change in temperature. The TAN, TBN, and sulphated ash are higher for synthetic oils. This may be due to the presence of higher concentrations of additives in them. The TAN values are fairly in the range of $0.5-2.25$ for the selected lubricants. The synthetic lubricants with low viscosity at 40 and $100^{\circ} \mathrm{C}$ possess a very high VI. This may be due to the presence of VI modifiers in the oil. The TBN values for the oils are in the range of 9-15 $\mathrm{mg} \mathrm{KOH} / \mathrm{g}$, with synthetic oils having high TBN values. The sulphated ash content is almost similar around 1\% wt for all the selected lubricants.

The results for the trace metal analysis are given in Table 4 . The results reveal the presence of very high concentrations of extreme pressure additives containing elements like zinc, phosphorous, and molybdenum. The synthetic oils show high concentrations of $\mathrm{Zn}$ and $\mathrm{P}$ and almost negligible Mo. Among the selected lubricants, $\mathrm{L}_{2}$ has highest additive concentration with $\mathrm{Zn}=977, \mathrm{Mo}=93$, and $\mathrm{P}=894 \mathrm{mg} / \mathrm{l}$. The presence of zinc, molybdenum, and phosphorus has a direct influence on the friction and wear behavior of the lubricants.

\subsection{Rheological Investigations}

3.2.1. Variation of Viscosity with Temperature. The variation in dynamic viscosity with temperature is shown in Figure 3. It is observed that the coefficient of viscosity decreases monotonically with increase in temperature. As shown in
TABLE 4: Trace metal analysis.

\begin{tabular}{lcccc}
\hline \multirow{2}{*}{ Sl. number } & \multirow{2}{*}{ Lubricant code } & \multicolumn{3}{c}{ Element $(\mathrm{mg} / \mathrm{l})$} \\
& & $\mathrm{Zn}$ & Mo & $\mathrm{P}$ \\
\hline 1 & $\mathrm{~L}_{1}$ & 549.10 & 36.60 & 512.30 \\
2 & $\mathrm{~L}_{2}$ & 977.10 & 93.30 & 893.50 \\
3 & $\mathrm{~L}_{3}$ & 724.60 & 50.00 & 677.60 \\
4 & $\mathrm{~L}_{4}$ & 907.10 & 1.00 & 857.90 \\
5 & $\mathrm{~L}_{5}$ & 924.60 & $<1.00$ & 877.90 \\
\hline
\end{tabular}

Figure 3 the decrease is not linear; however, it is in tandem with the general trends of variation of lubricant viscosity with temperature. Lubricant $\mathrm{L}_{2}$ has the highest value for coefficient of viscosity, that is, $0.5 \mathrm{~Pa}-\mathrm{s}$ at $293 \mathrm{~K}$. It has the largest negative gradient with temperature indicating that it is more susceptible to temperature variations. $\mathrm{L}_{4}$ and $\mathrm{L}_{5}$ have smaller values of dynamic viscosity being synthetic lubricants. But these lubricants show better stability as compared to the mineral based lubricants as they have smaller negative temperature gradient of viscosity.

The variation of viscosity with temperature for the selected lubricants with the help of curve fitting technique is found to obey Reynolds' equation [18] given by

$$
\mu_{0}=b e^{-a T_{A}}
$$

where $\mu_{0}$ is the dynamic viscosity at atmospheric pressure and $T_{A}$ is absolute temperature. 


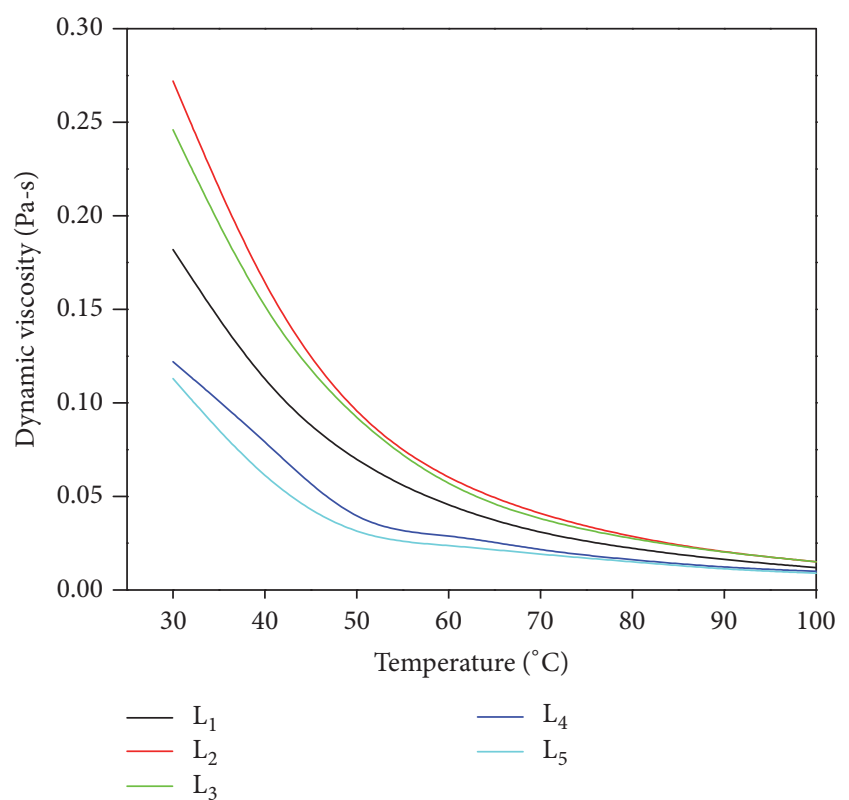

Figure 3: Variation of viscosity with temperature.

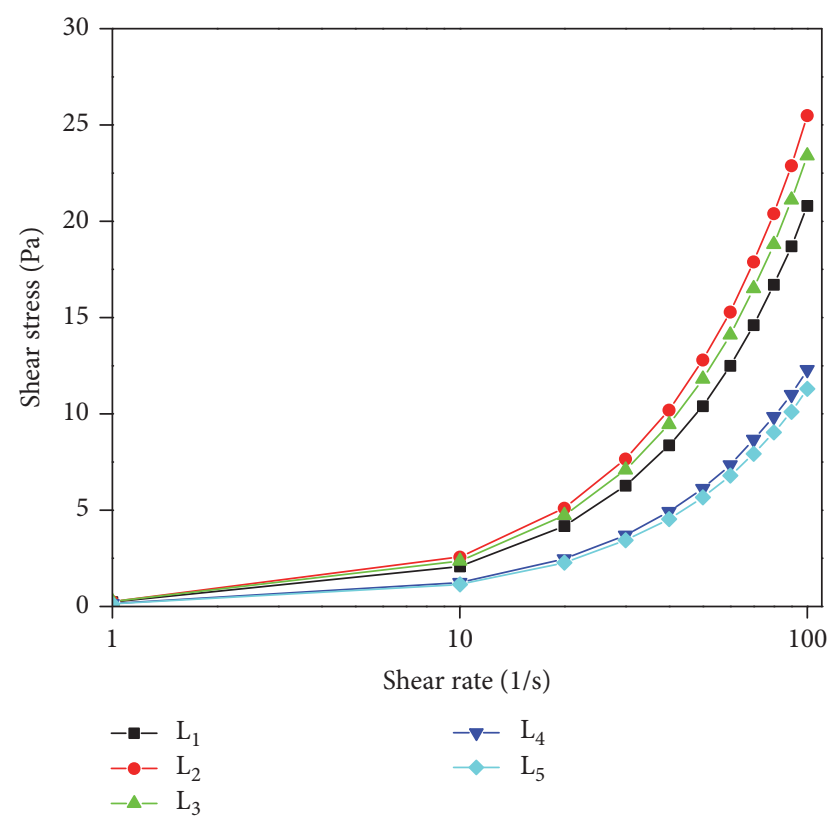

FIGURE 4: Variation of shear stress with shear rate for the lubricants.

3.2.2. Variation of Shear Stress with Shear Rate. The variation of shear stress/shear rate is shown in Figure 4. As observed from Figure 4, all the selected lubricants describe nonlinear behavior representing non-Newtonian behavior indicating presence of viscoelasticity. All of them have yield stress showing viscoplastic nature with $\mathrm{L}_{2}$ having highest value.

Utilizing the experimental data represented in Figure 4, curve fitting was performed with the help of curve fitting tool box in MATLAB software. The best cure fit equation thus obtained is given by

$$
\tau=m\left(\frac{\partial u}{\partial y}\right)^{n}
$$

TABLE 5: Power law index of the lubricants.

\begin{tabular}{lcc}
\hline Sl. number & Lubricant code & Power law index \\
\hline 1 & $\mathrm{~L}_{1}$ & 0.9967 \\
2 & $\mathrm{~L}_{2}$ & 0.9969 \\
3 & $\mathrm{~L}_{3}$ & 0.9916 \\
4 & $\mathrm{~L}_{4}$ & 0.9940 \\
5 & $\mathrm{~L}_{5}$ & 0.9998 \\
\hline
\end{tabular}

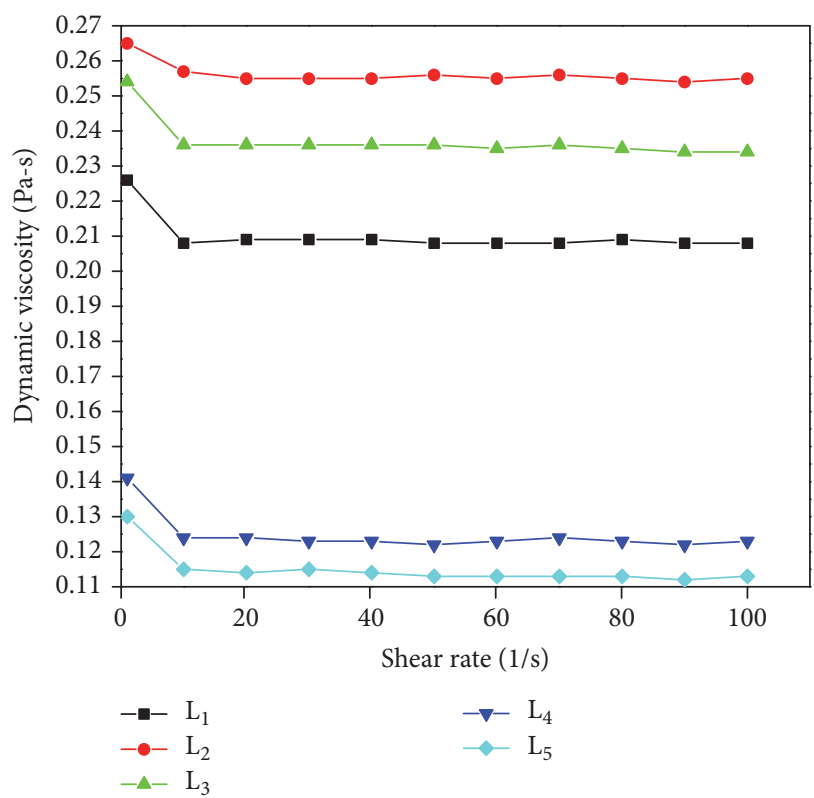

FIGURE 5: Variation of viscosity with shear rate for the lubricants.

Equation (2) represents the flow behavior of power law fluid. The value of power law index " $n$ " signifies the Newtonian and non-Newtonian behavior of lubricants. " $n$ " $<1$ represents shear thinning behavior, " $n$ " $>1$ represents shear thickening, and $n=1$ represents the Newtonian fluid. The power law index values as obtained from the curve fitting procedure are given in Table 5 . The values of " $n$ " for the lubricants are close to less than 1 representing shear thinning behavior of the lubricants. This further confirms that the lubricants represent non-Newtonian behavior.

3.2.3. Variation of Viscosity with Shear Rate. The variation of viscosity with shear rate is shown in Figure 5. As observed from Figure 5 the viscosity initially decreases with increase of shear rate. This behavior is observed at lower shear rates, that is, shear rate $<10 / \mathrm{s}$. At higher shear rates there is no significant variation and the coefficient of viscosity is almost constant over the entire range of shear rate. The lubricant $\mathrm{L}_{1}$ shows the largest variation of viscosity with shear rate and $\mathrm{L}_{2}$ the least. Beyond shear rate of $10 / \mathrm{s}$ the viscosity is almost independent of shear rate. Decrease of viscosity with shear rate is more pronounced for $\mathrm{L}_{1}$ showing more shear thinning and hence more viscoelastic behavior. Small values of dynamic viscosity for L4 and L5 are attributed to their synthetic origin and having SAE grade $5 \mathrm{~W}-40$. 
TABLE 6: Tribological performance of lubricants.

\begin{tabular}{lccc}
\hline Sl. number & Lubricant code & Coefficient of friction & Average wear scar diameter $(\mathrm{mm})$ \\
\hline 1 & $\mathrm{~L}_{1}$ & 0.1429 & 0.710 \\
2 & $\mathrm{~L}_{2}$ & 0.1155 & 0.746 \\
3 & $\mathrm{~L}_{3}$ & 0.1416 & 0.676 \\
4 & $\mathrm{~L}_{4}$ & 0.0890 & 0.391 \\
5 & $\mathrm{~L}_{5}$ & 0.0881 & 0.446 \\
\hline
\end{tabular}

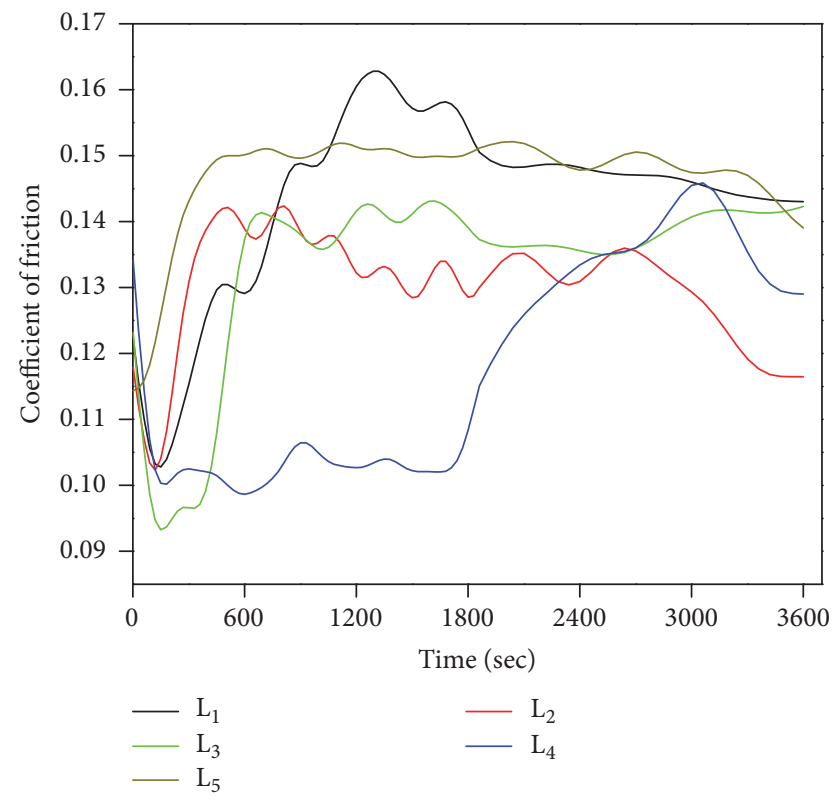

FIGURE 6: Friction coefficient versus time in seconds for $\mathrm{L}_{1}, \mathrm{~L}_{2}, \mathrm{~L}_{3}$, $\mathrm{L}_{4}$, and $\mathrm{L}_{5}$.

3.3. Tribological Investigations. The tribological performance of lubricants is defined in terms of their friction and wear behavior.

3.3.1. Friction Behavior. Figure 6 shows the variation in coefficient of friction for the lubricants over the entire experimental duration. It is observed from Figure 6 that the coefficient of friction increased during the early stage of experiment and later on remained almost constant. Due to the initiation of the wear scar the coefficient of friction increased in the early stage; later on due to the rubbing wear the coefficient of friction became almost constant. The kinetic friction, that is, the coefficient of friction at the end of the test, is the highest for lubricant $\mathrm{L}_{1}(\mu=$ $0.1429)$ and lowest for lubricant $\mathrm{L}_{2}(\mu=0.1155)$. This behavior of lubricants can be attributed to the presence of extreme pressure and antifriction additives. Lubricant $\mathrm{L}_{1}$ has relatively lower concentrations of $\mathrm{Zn}$ and $\mathrm{P}$ as evident from Table 4, while $\mathrm{L}_{2}$ has got the highest concentration of these elements. In case of synthetic base lubricants, the friction coefficient of $\mu=0.0890$ and $\mu=0.0881$ is observed for lubricants $L_{4}$ and $\mathrm{L}_{5}$, respectively. Though synthetic oils possess a very low viscosity, yet higher concentrations of $\mathrm{Zn}$ and $\mathrm{P}$ present in them enhance the film forming capability of these oils at the given test load, hence decreasing the friction coefficient when compared with the mineral based lubricants. The lubricants are often blended with zinc dialkyl dithiophosphate (ZDDP) as multifunctional additive. The $\mathrm{Zn}$ and $\mathrm{P}$ resent in this additive form the polar moieties which are able to adhere on the steel surface and protect the surface from damage. This adsorbed layer of additive is known as boundary film which under pressure (applied load) gets strengthened, thereby reducing the friction and wear.

3.3.2. Wear Behavior. The wear scars as observed on the ball test specimens are shown in Figure 7. The morphology of wear scar reveals normal rubbing wear within the contact. The rubbing marks are distinctly visible along the sliding direction.

For a better comparison of test results, the coefficient of friction and WSD is tabulated in Table 6. The lubricant $\mathrm{L}_{4}$ reported the best antiwear performance with WSD of $0.391 \mathrm{~mm}$, while the lubricant $\mathrm{L}_{2}$ reported the poorest performance with WSD of $0.746 \mathrm{~mm}$.

3.3.3. Postexperimental Analysis. Figure 8 shows the SEM micrographs of used ball test specimens. The SEM micrographs reveal that the wear surfaces have undergone normal rubbing wear under the influence of load in the sliding direction. The wear tracks observed are parallel to the direction of sliding. The lubricant $\mathrm{L}_{4}$ and $\mathrm{L}_{5}$ show a smoother surface with some edge serrations along the wear track. The surface smoothening must have occurred due to the rubbing of the asperities under the applied load. Similarly the micrograph for $\mathrm{L}_{2}$ lubricated specimen shows severe wear with small micropits. It also shows scuffing on the surface. The $\mathrm{L}_{1}$ lubricated specimen has smooth wear tracks representing smoothening of surface asperities. Also the wear associated with this lubricant is very low due to this smoothening action. The $\mathrm{L}_{3}$ lubricated specimen shows rigorous scuffing on the steel surface. The scuffing marks are deeper and hence a larger wear scar diameter is observed with this lubricant. The SEM micrograph for the $\mathrm{L}_{3}$ lubricated specimen reveals some surface distress with scuffing in the direction of sliding. The surface damage is observed in the form of nonuniform removal of material from the surface.

The EDX analysis for the specimens reveals the presence of elements like zinc, sulphur, phosphorus, and so on, which signifies that a thin boundary layer of lubricant is formed on the steel surfaces. The boundary films formed with the help of extreme pressure additives help in protecting the surfaces from further damage. 


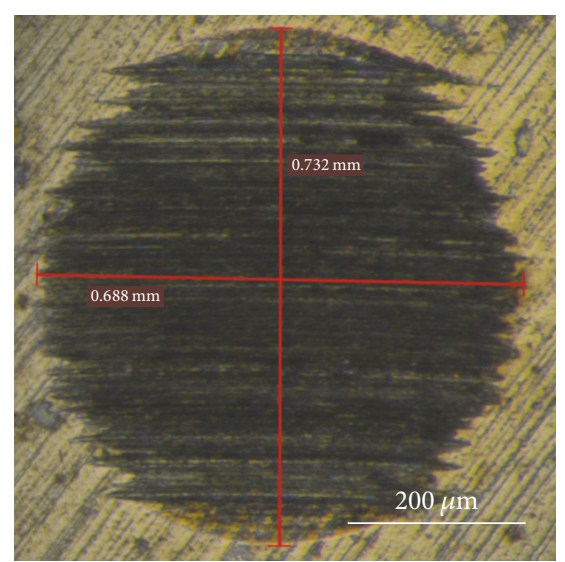

(a)

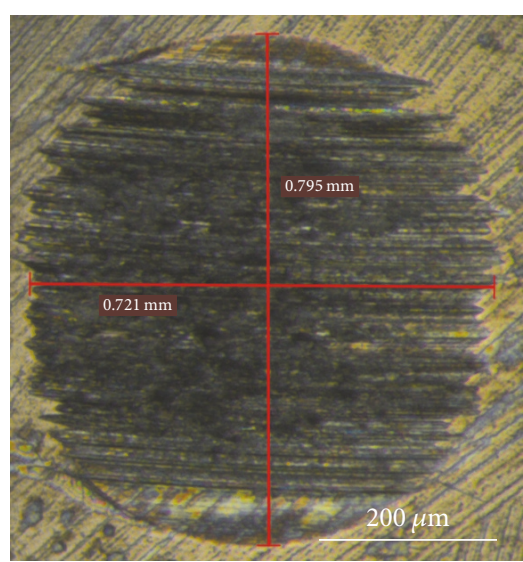

(b)

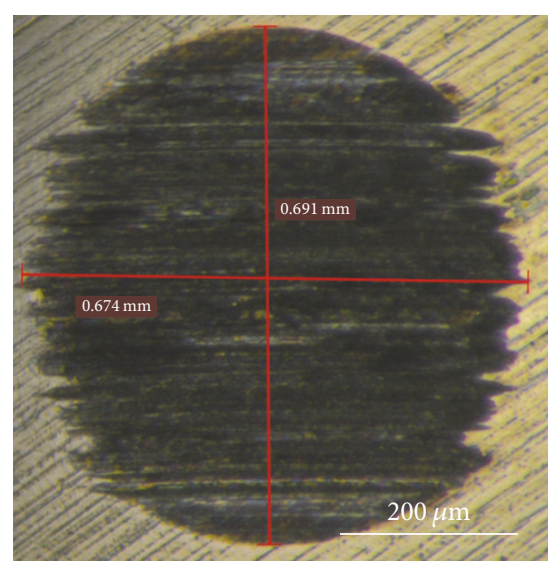

(c)

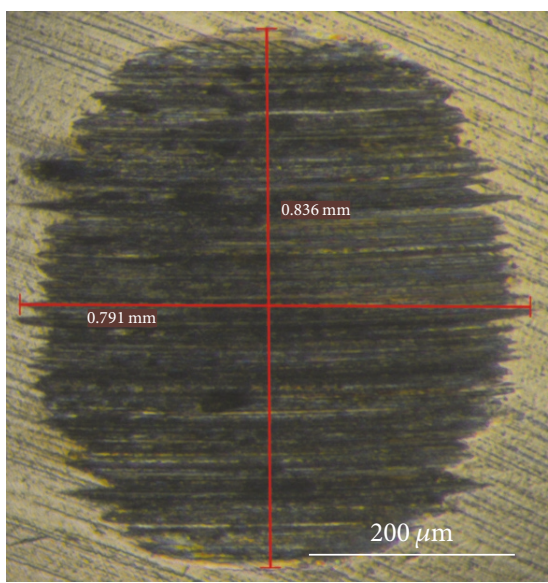

(d)

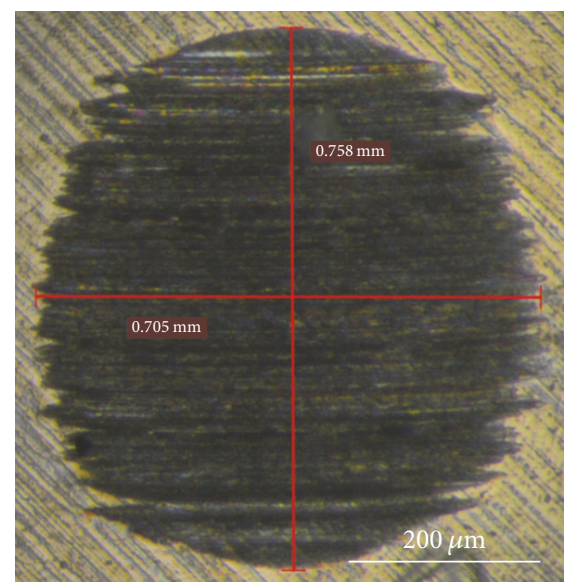

(e)

Figure 7: Wear scar diameters for the lubricants (a) $\mathrm{L}_{1}$, (b) $\mathrm{L}_{2}$, (c) $\mathrm{L}_{3}$, (d) $\mathrm{L}_{4}$, and (e) $\mathrm{L}_{5}$.

3.4. Correlation Analysis. Correlation analysis predicts the association between two or more variables and infers the strength of the relationship among them. The value of correlation coefficient " $r$ " reflects the extent to which the two individual variables are related [19]. The value of $r$ ranges between -1 and +1 . +1 value indicates perfectly positive correlation while -1 indicates perfectly negative correlation. The " $r$ " is determined with the help of (i) covariance $\operatorname{Cov}(x, y)$ between any two variables that measures the variability of the $(x, y)$ pairs around the mean of $x$ and mean of $y$ and (ii) sample variances of $x$ and $y$, that is, $S_{x}^{2}$ and $S_{y}^{2}$ that represent the variability of $x$-scores and $y$-scores around their respective sample means $\bar{X}$ and $\bar{Y}$, respectively. Thus, the " $r$ " is calculated using the formula

$$
r=\frac{\operatorname{Cov}(x, y)}{\sqrt{S_{x}^{2} S_{y}^{2}}} .
$$

The lubricant properties given in Table 3 and the performance characteristics given in Table 6 have been therefore used to determine the correlation coefficients. Table 7 gives the correlation coefficients obtained using correlation analysis among different physicochemical and tribological parameters.
On examining the correlation coefficients of physicochemical and tribological properties, it is observed that the kinematic viscosity at $40^{\circ} \mathrm{C}$ has a positive correlation coefficient of 0.83 indicating that density affects viscosity directly. Positive correlation of 0.92 between metal additive Mo and density and of 0.95 between Mo and kinematic viscosity at $40^{\circ} \mathrm{C}$ shows that Mo affects the density and kinematic viscosity of the lubricant positively. Very high positive correlation coefficient of 0.94 between VI and TBN is a clear indicator that more neutralization of acid produced improves the VI of oil, thus prolonging the operational life. Trace metals $\mathrm{Zn}$ and $\mathrm{P}$ have very high value of correlation coefficients 0.96 and 0.98 , respectively, with TAN indicating that though they improve the performance of the oil, yet they cause increase in lubricant acidity. This subsequently leads to increase in friction as interaction between the surfaces enhances oxidation and oxides in general get adsorbed on the surface [20]. Negative correlation of significance between WSD and TAN with value -0.55 and between COF and TAN with value -0.84 indicates that the increase in the value of TAN does not affect COF and WSD as TBN also has strong negative correlation of -0.92 with $\mathrm{COF}$ and -0.91 with WSD. It means the formation of acids in the process is combated by 

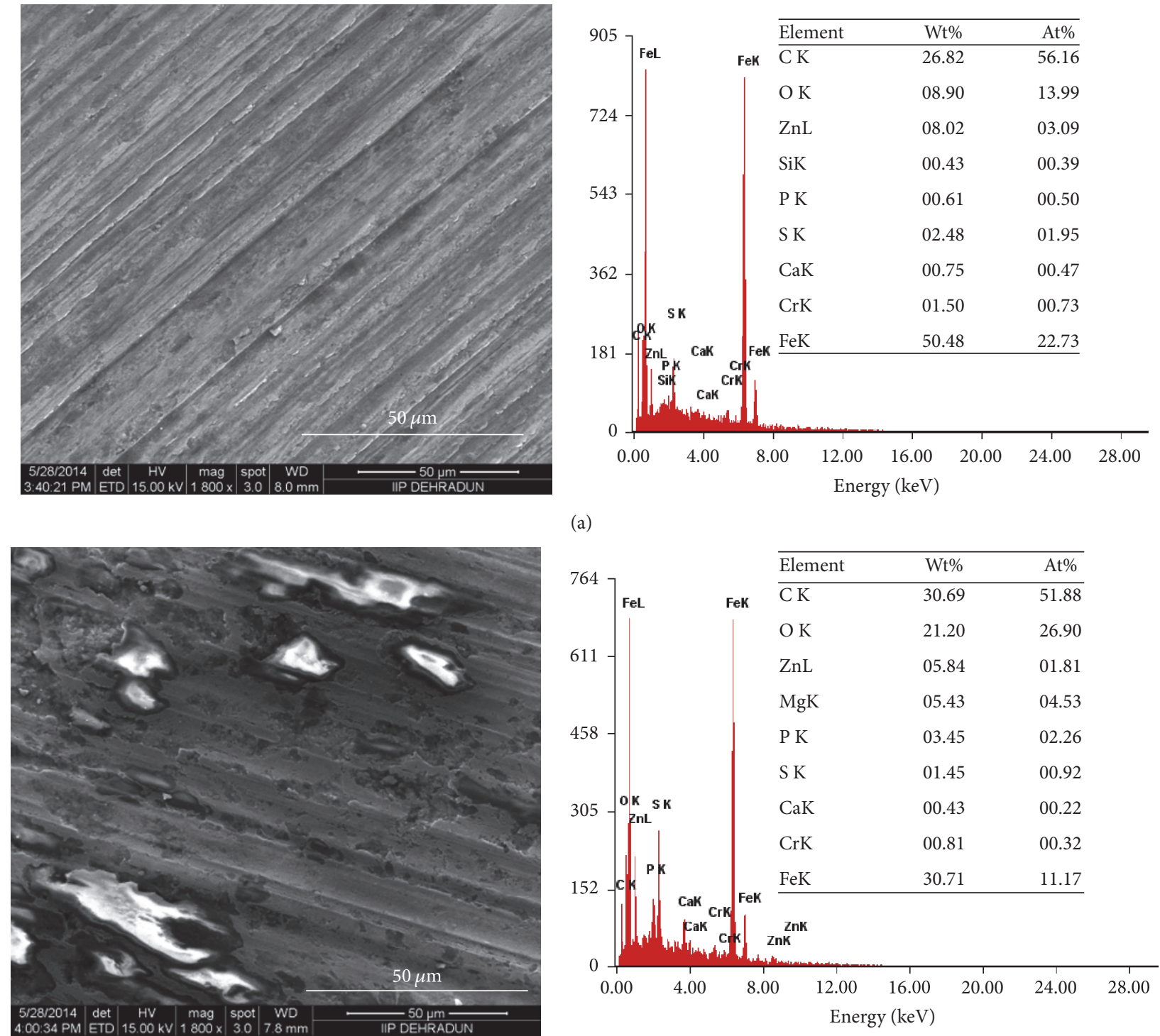

(b)
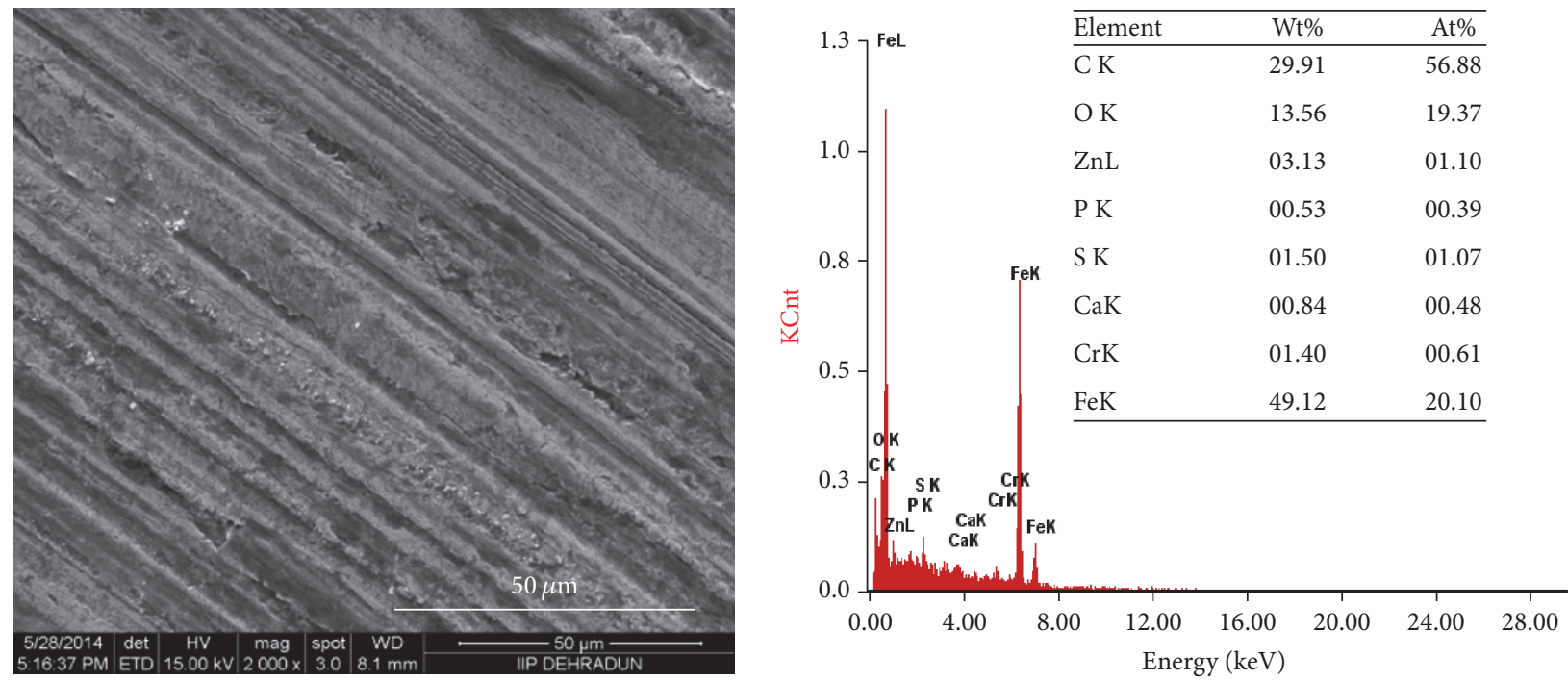

(c)

Figure 8: Continued. 

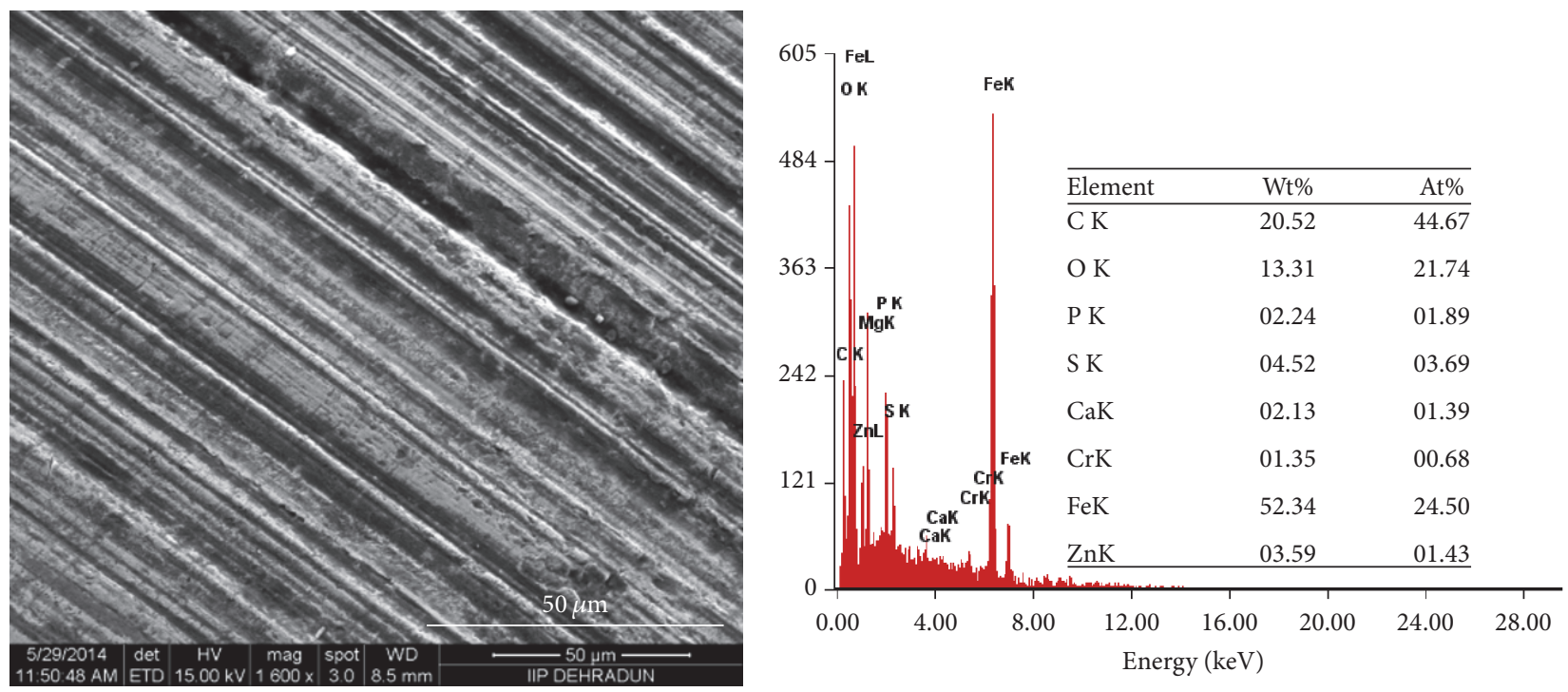

(d)
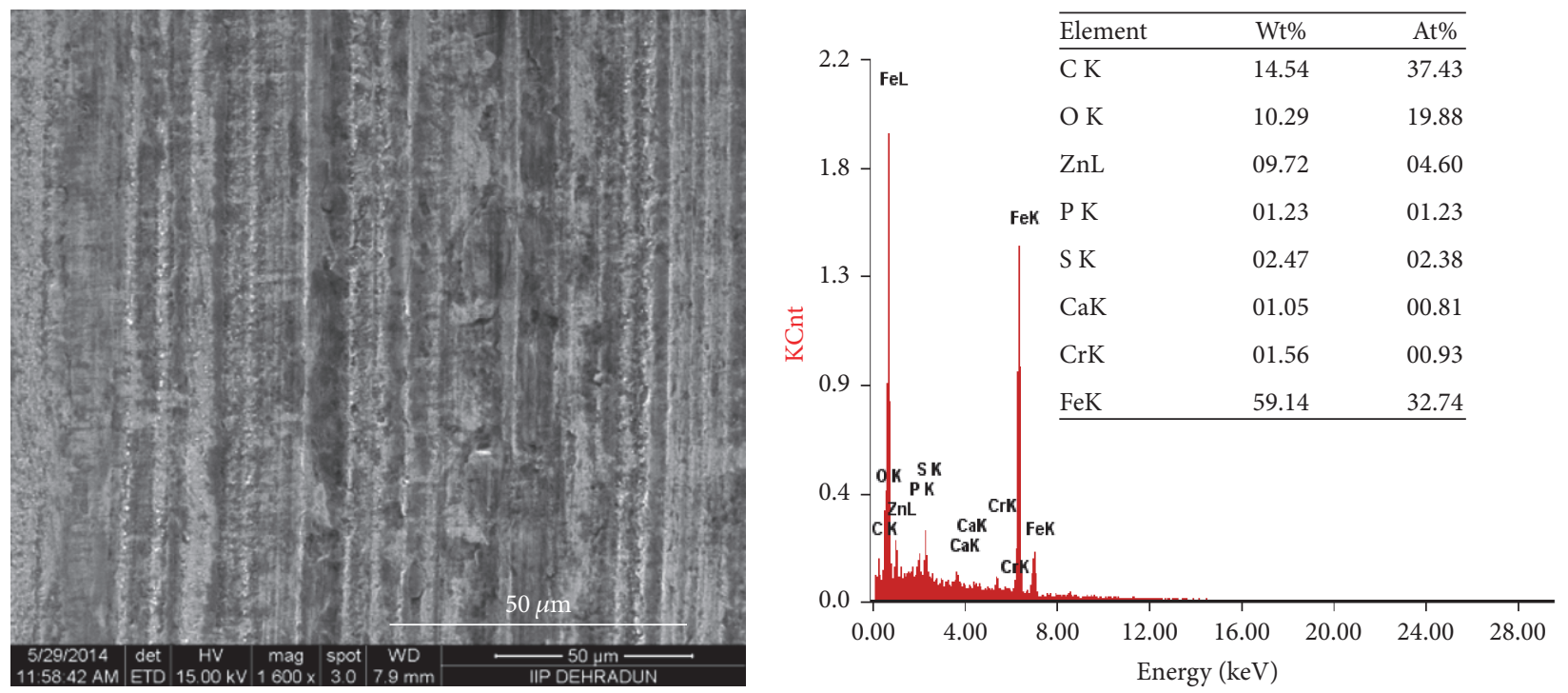

(e)

Figure 8: SEM/EDX micrographs for the lubricants (a) $\mathrm{L}_{1}$, (b) $\mathrm{L}_{2}$, (c) $\mathrm{L}_{3}$, (d) $\mathrm{L}_{4}$, and (e) $\mathrm{L}_{5}$.

the presence of bases in the additive package. Strong positive correlation of 0.82 is incidental as it is a proven fact that they are almost unrelated as some lubricants give antifriction properties while others only give antiwear properties.

3.5. Regression Analysis for Lubricant Properties. Regression analysis has been performed for estimating the causal relationships for coefficient of friction and WSD with the physicochemical characteristic properties. Linear regression is the technique used for establishing causal relationship between a dependent variable and two or more independent variables. This helps to establish a relationship between the parameters of interest. The dependent variable, coefficient of friction $(\mu)$, and independent variables, density @ $15^{\circ} \mathrm{C}(\rho)$, kinematic viscosity @ $40^{\circ} \mathrm{C}\left(\nu_{40}\right)$, and TAN, for the selected lubricants are given in Table 8.
The first-order multiple regression model was implemented on the data given in Table 8 and the regression statistics was established. The regression statistics involved determination of the values for correlation coefficient $\left(R^{2}\right)$ and the standard error $(E)$. The values obtained in the present analysis are $R^{2}=0.82$ and $E=0.01$ representing strong relationship among the variables. Subsequently ANOVA (analysis of variance) was performed to determine the level of variability within the regression model. The significance and parameters, namely, degrees of freedom (df), sum of squares (SS), and the mean square (MS), obtained from ANOVA are given in Table 9.

Inference for multiple regression was later drawn by fitting a linear equation to the observed data. The least square fit was assumed and the line residuals were determined. The test statistics, that is, the ratio of slope and standard deviation 
TABLE 7: Correlation coefficient matrix for lubricant properties (physicochemical and tribological).

\begin{tabular}{|c|c|c|c|c|c|c|c|c|c|c|c|c|}
\hline & $\begin{array}{c}\rho @ 15^{\circ} \mathrm{C} \\
\mathrm{g}-\mathrm{cm}^{-3}\end{array}$ & $v @ 40^{\circ} \mathrm{C}$ & $v @ 100^{\circ} \mathrm{C}$ & VI & TAN & $\mathrm{TBN}$ & $\begin{array}{c}\text { Sulphated } \\
\text { ash }\end{array}$ & $\mathrm{Zn}$ & Mo & $\mathrm{P}$ & $\mathrm{COF}$ & WSD \\
\hline$\rho @ 15^{\circ} \mathrm{Cg} \mathrm{cm}^{-3}$ & $1^{*}$ & 0.83 & 0.73 & 0.73 & 0.08 & 0.59 & -0.68 & 0.08 & 0.92 & 0.01 & 0.41 & 0.75 \\
\hline$v @ 40^{\circ} \mathrm{C}$ & 0.83 & $1^{*}$ & $.91^{*}$ & 0.90 & -0.53 & 0.91 & -0.50 & -0.15 & 0.95 & 0.22 & 0.73 & 0.78 \\
\hline$v @ 100^{\circ} \mathrm{C}$ & 0.73 & $.91^{*}$ & $1^{*}$ & 0.76 & $-0.34^{*}$ & 0.85 & $-0.46^{*}$ & 0.02 & 0.88 & -0.04 & 0.68 & 0.81 \\
\hline VI & -0.73 & -0.90 & -0.76 & $1^{*}$ & 0.71 & 0.94 & 0.13 & 0.53 & -0.83 & 0.60 & -0.92 & -0.97 \\
\hline TAN & -0.08 & -0.53 & $-0.34^{*}$ & 0.71 & $1^{*}$ & 0.70 & 0.33 & 0.96 & -0.20 & 0.98 & -0.84 & -0.55 \\
\hline TBN & -0.59 & -0.91 & -0.85 & 0.94 & 0.70 & $1^{*}$ & 0.08 & 0.50 & -0.76 & 0.56 & -0.92 & -0.91 \\
\hline $\begin{array}{l}\text { Sulphated } \\
\text { Ash }\end{array}$ & -0.68 & -0.50 & $-0.46^{*}$ & 0.13 & 0.33 & 0.08 & $1^{*}$ & 0.51 & -0.46 & -0.47 & -0.31 & -0.45 \\
\hline $\mathrm{Zn}$ & 0.08 & -0.15 & 0.02 & 0.53 & 0.96 & 0.50 & -0.51 & $1^{*}$ & 0.03 & 0.99 & -0.79 & -0.42 \\
\hline Mo & 0.92 & 0.95 & 0.88 & 0.83 & 0.20 & 0.76 & -0.46 & 0.03 & $1^{*}$ & -0.04 & 0.55 & 0.88 \\
\hline$P$ & 0.01 & -0.22 & -0.04 & 0.60 & 0.98 & 0.56 & -0.47 & 0.99 & -0.04 & $1^{*}$ & -0.83 & -0.49 \\
\hline $\mathrm{COF}$ & 0.41 & 0.73 & 0.68 & -0.84 & -0.84 & -0.92 & -0.31 & -0.79 & 0.55 & -0.83 & $1^{*}$ & $0.82^{*}$ \\
\hline WSD & 0.75 & 0.91 & 0.76 & -0.97 & -0.55 & -0.91 & -0.45 & 0.88 & -0.35 & 0.65 & $0.82^{*}$ & $1^{*}$ \\
\hline
\end{tabular}

*Not relevant.

TABLE 8: Data for regression analysis.

\begin{tabular}{lcccc}
\hline Sl. number & COF $(\mu)$ & Density, $(\rho) @ 15^{\circ} \mathrm{C}$ & Kinematic viscosity, $v_{40} @ 40^{\circ} \mathrm{C}$ & TAN \\
\hline 1 & 0.1429 & 0.8711 & 123.06 & 0.44 \\
2 & 0.1155 & 0.8910 & 166.71 & 1.93 \\
3 & 0.1416 & 0.8695 & 154.93 & 0.93 \\
4 & 0.0890 & 0.8655 & 83.68 & 2.13 \\
5 & 0.0881 & 0.8526 & 79.82 & 2 \\
\hline
\end{tabular}

TABle 9: Analysis of variance (ANOVA).

\begin{tabular}{lccccc}
\hline Source & df & SS & MS & $F$ & Significance $F$ \\
\hline Regression & 3 & 0.003263 & 0.001088 & 10.8076 & \\
Residual & 7 & 0.000705 & 0.000101 & \\
Total & 10 & 0.003968 & & \\
\hline
\end{tabular}

TABLE 10: Inference in linear regression.

\begin{tabular}{lcccc}
\hline & Coefficient & Standard error & $t$-test & $P$ value \\
\hline Intercept & 0.085467 & 0.2280 & 0.3748 & 0.7189 \\
Density @ $15^{\circ} \mathrm{C}(\rho)$ & 0.033305 & 0.2740 & 0.1215 & 0.9067 \\
Kinematic viscosity @ $40^{\circ} \mathrm{C}\left(v_{40}\right)$ & 0.000241 & 0.0001 & 1.7749 & 0.1192 \\
TAN & -0.02154 & 0.0064 & -3.3717 & 0.01189 \\
\hline
\end{tabular}

in each observation, is given in Table 10. The $P$ value of inference provides the probability value associated with the two-sided test.

After determining the coefficient of intercepts and independent variables the regression equation is written in the linear form as

$$
\begin{aligned}
& \text { Coefficient of friction: } \mu \\
& =0.085467+0.033305 \rho+0.000241 \nu_{40} \\
& -0.02154 \mathrm{TAN},
\end{aligned}
$$

where $\rho$ is density at $15^{\circ} \mathrm{C}, v_{40}$ is kinematic viscosity @ $40^{\circ} \mathrm{C}$, and TAN is total acid number.

Significance $F$ (Table 10) for relation (4) is 0.005098 which is much less than 0.1 , signifying that the formula is more reliable.

\section{Conclusion}

In the present study, experimental investigations have been carried out to study the performance variability and establish a correlation between the characteristic properties of engine oils. The experiments have been performed to investigate the 
physicochemical, rheological, and tribological properties of mono- and multigrade engine oils of different API performance standards. Thus, on the basis of the investigations made, the following broad conclusions are drawn:

(i) The commercial engine oils are nearly similar in their physicochemical characteristics. However, the synthetic lubricants possess high VI and TBN and higher concentrations of additives as compared to mineral based oils.

(ii) The rheological behavior of lubricants reveals that the variation of viscosity with temperature for the tested engine oils obeys Reynolds' equation. The lubricants describe non-Newtonian shear thinning behavior with the power law index values close to 0.99 .

(iii) The tribological performance of lubricants reveals that the synthetic base lubricant possesses superior antifriction and antiwear properties than the mineral base lubricants. The coefficient of friction varies from 0.0881 to 0.1429 for the tested lubricants. Similarly the wear scar diameter varies from $0.391 \mathrm{~mm}$ to $0.746 \mathrm{~mm}$ for the tested lubricants The tribo performance of the lubricants is predominantly influenced by the viscosity and the additives present.

(iv) The worn out surfaces reveal that the synthetic base lubricants result in less surface distress while the contemporary mineral base lubricants show rigorous scuffing. All the lubricants are capable of forming thin boundary film on the steel surfaces.

(v) The correlation analysis reveals that the friction and wear behavior of lubricants is influenced by their viscosity. The viscosity in turn is influenced by density, TAN, and TBN values. Moreover, the TAN and TBN are influenced by the concentrations of the trace metals present in the additives used.

(vi) An empirical relation correlating friction, viscosity, density, and TAN values of the lubricants is given by $\mu=0.085467+0.033305 \rho+0.000241 \nu_{40}-0.02154$ TAN which gives fair degree of reliability with maximum deviation of $14 \%$ from the experimental results.

\section{Nomenclature}

TAN: Total acid number

TBN: Total base number

ICPAES: Inductively coupled plasma emission spectrometer

FBT: $\quad$ Four-ball tribotester

WSD: Wear scar diameter

EP: $\quad$ Extreme pressure

SEM: Scanning electron microscope

VI: $\quad$ Viscosity index

$\mu_{0}: \quad$ Dynamic viscosity

$T_{A}$ : $\quad$ Absolute temperature

$n$ : $\quad$ Power law index

$\mu$ : $\quad$ Coefficient of friction

$\rho: \quad$ Density at $15^{\circ} \mathrm{C}$ $v_{40}: \quad$ Kinematic viscosity at $40^{\circ} \mathrm{C}$

$\nu_{100}$ : $\quad$ Kinematic viscosity at $100^{\circ} \mathrm{C}$

Multiple R: Coefficient of multiple correlations

$R^{2}$ : $\quad$ Coefficient of determination

SS: $\quad$ Sum of squares

df: $\quad$ Degree of freedom

MS: $\quad$ Mean squared

Residual MS: Mean squared error

SS Residual: Residual sum of squares

SS Total: Total sum of squares.

\section{Conflicts of Interest}

The authors declare that there are no conflicts of interest regarding the publication of this paper.

\section{References}

[1] S. Q. A. Rizvi, A Comprehensive Review of Lubricant Chemistry, Technology, Selection and Design, ASTM International, Conshocken, PA, USA, 2009.

[2] C. Meunier, D. Mazuyer, P. Vergne, M. E. Fassi, and J. Obiols, "orrelation between the film forming ability and rheological properties of new and aged low sulfated ash, phosphorus and sulfur (low SAPS) automotive lubricants," Tribology Transactions, vol. 52, no. 4, pp. 501-510, 2009.

[3] R. B. Bird, R. C. Armsrong, and O. Hassager, Dynamics of Polymeric Liquids Vol. 1: Fluid Mechanics, Wiley, New York, NY, USA, 2nd edition, 1987.

[4] N. Sharma, R. K. Sharma, N. Sunil, and S. Kango, "A comparative study for lubrication of surface textured porous journal bearing with two different non-Newtonian fluid models," International Journal of Surface Science and Engineering, vol. 10, no. 5, p. 485, 2016.

[5] P. Schümmer, "Mechanics of non-newtonian fluids," Chemie Ingenieur Technik, vol. 51, no. 7, p. 766, 1979.

[6] J. Frene, M. Arghir, and H. Zaidi, "Regimes of lubrication in lubricated contacts," International Journal of Surface Science and Engineering, vol. 4, no. 2, pp. 175-190, 2010.

[7] J. Abdo, "Design of experiments technique for characterisation of friction in dry contact," International Journal of Surface Science and Engineering, vol. 2, no. 1-2, pp. 120-138, 2008.

[8] M. Trzos, M. Szczerek, and W. Tuszynski, "A study on the possibility of the Brugger test application for differentiation between the API GL performance levels of gear oils," Archives of Civil and Mechanical Engineering, vol. 13, no. 1, pp. 14-20, 2013.

[9] G. D. Thakre and M. R. Tyagi, "Study on variation of triboperformance of commercial engine oils," Industrial Lubrication and Tribology, vol. 65, no. 5, pp. 341-347, 2013.

[10] R. D. Gaikwad and P. Swamy, "Physico-chemical and viscosity studies in some seed oils from wild \& cultivated plants," Acta Chimica Slovenica, vol. 55, no. 3, pp. 683-687, 2008.

[11] G. S. Cholakov, K. G. Stanulov, P. Devenski, and H. A. Iontchev, "Quantitative estimation and prediction of tribological performance of pure additive compounds through computer modelling," Wear, vol. 216, no. 2, pp. 194-201, 1998.

[12] M. Roegiers and B. Zhmud, "Property blending relationships for binary mixtures of mineral oil \& elektrionised vegetable oil: viscosity solvent power \& seal compatibility index," Lubrication Science, vol. 23, no. 6, pp. 263-278, 2011. 
[13] B. K. Sharma and A. J. Stipanovic, "Pressure viscosity coefficient of lubricant base oils as estimated by nuclear magnetic resonance spectroscopy," Industrial and Engineering Chemistry Research, vol. 41, no. 19, pp. 4889-4898, 2002.

[14] C. Barus, "Isothermals, isopiestics and isometrics relative to viscosity," American Journal of Science, vol. 45, no. 266, pp. 8796, 1893.

[15] P. W. Michael, J. M. Garcia, S. S. Bair, M. T. Devlin, and A. Martini, "Lubricant Chemistry and Rheology Effects on Hydraulic Motor Starting Efficiency," Tribology Transactions, vol. 55, no. 5, pp. 549-557, 2012.

[16] S. Bair and F. Qureshi, "Time-temperature-pressure superposition in polymer thickened liquid lubricants," Journal of Tribology, vol. 136, no. 2, Article ID 021505, 6 pages, 2014.

[17] A. K. Yadav, G. Mishra, and R. Yadav, "Synthesis and ultrasonic characterization of nanofluid containing silver nanoparticles," Material Science An Indian Journal, vol. 5, no. 3, pp. 237-242, 2009.

[18] D. Knezevic and D. Savic, "Mathematical modelling of changing of dynamic viscosity, as a function of temperature and pressure, of mineral oils for hydraulic systems," 6 FactaUniversitatisSeries: Mechanical Engineering, vol. 4, no. 1, pp. 27-34, 2006.

[19] S. P. Washington, M. G. Karlaftis, and F. L. Mannering, Statistical and Econometric Methods for Transportation Data Analysis, CRC Press \& Francis Group, Boca Raton, Fla, USA, 2nd edition, 2010.

[20] D. H. Buckley, Surface Effects in Adhesion, Friction, Wear and Lubrication, Elsevier Scientific publishing Company Amsterdam, 1981. 


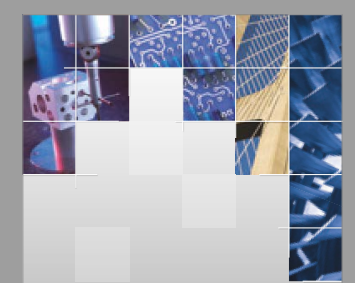

\section{Enfincering}
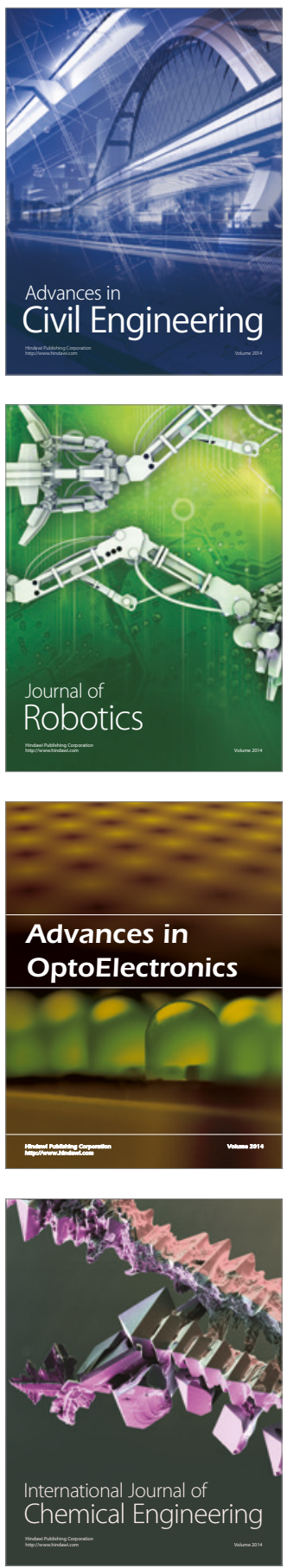

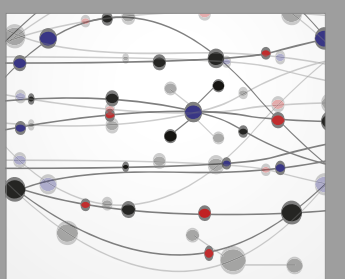

The Scientific World Journal

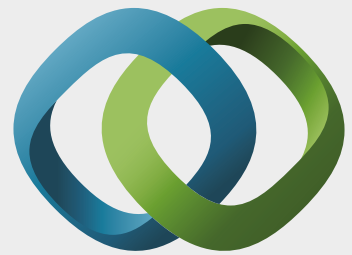

\section{Hindawi}

Submit your manuscripts at

https://www.hindawi.com
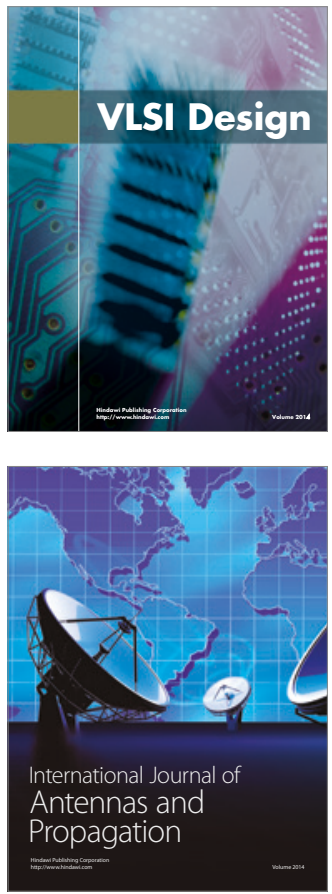

\section{Rotating}

Machinery
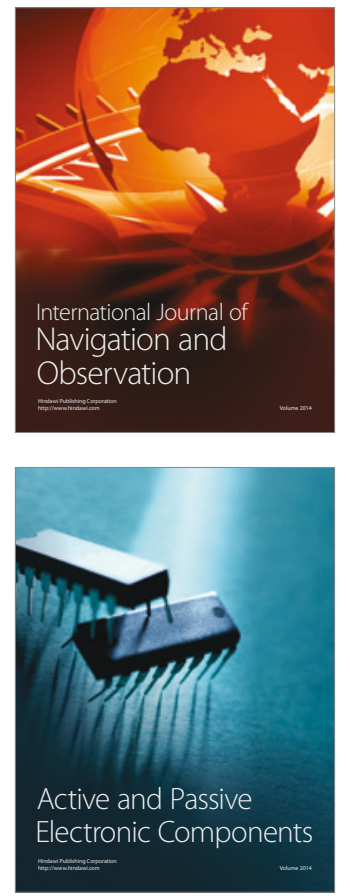
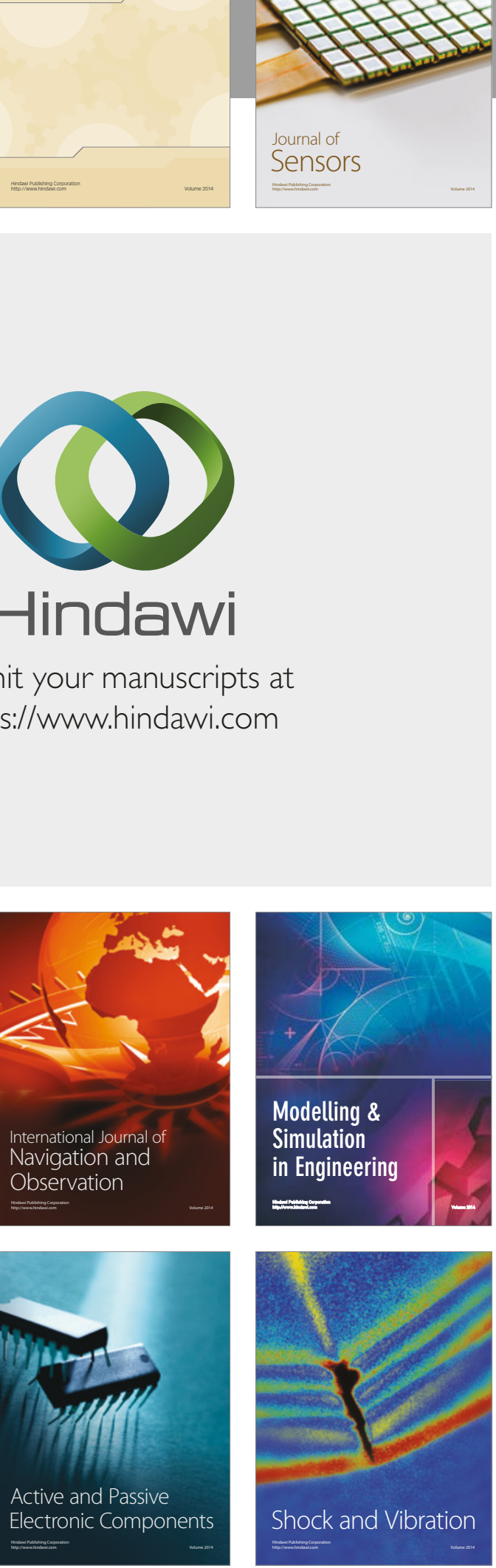
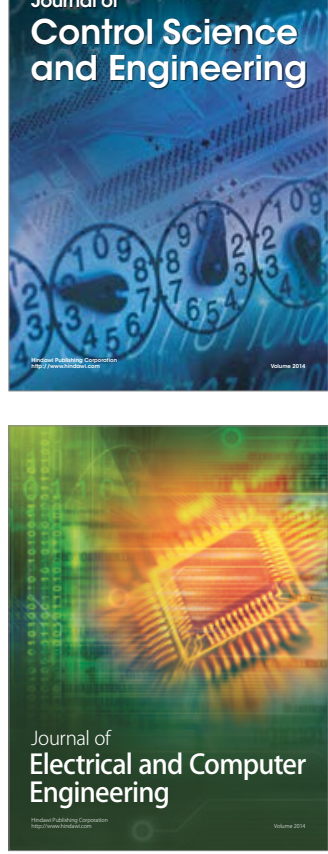

Distributed

Journal of

Control Science

and Engineering
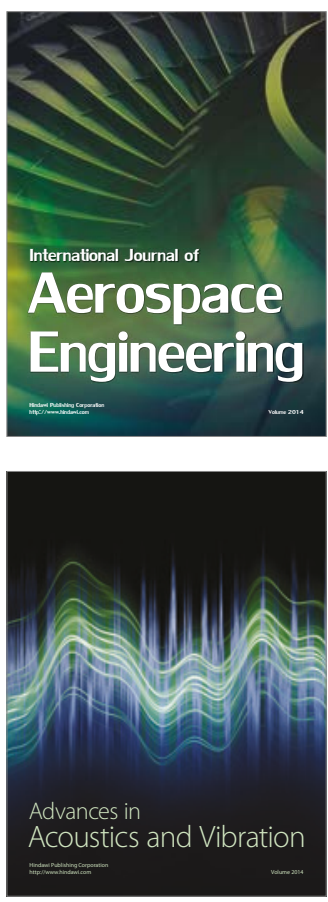

Sensor Networks 